ISSN 1112-9867

Special Issue

\title{
MEASUREMENT OF BRIX LEVEL OF MALAYSIAN LOCAL ORANGES AT RESONANCE FREQUENCY
}

\author{
H. Ghazali, R. Rosman ${ }^{*}$ and Z. Sharif \\ Faculty of Electrical Engineering, UniversitiTeknologi MARA, 40450 Shah Alam, Selangor, \\ Malaysia
}

Published online: 05 October 2017

\begin{abstract}
The production of citrus in worldwide has increased over the years. This is due to demand from consumer as well as positive progress in agriculture-related industry. Malaysia also produces a lot of citrus but at the same time statistics shows that the number of citrus being imported from other countries is also high. In order to maintain the quality of citrus production, a non-destructive method by using monopole antenna is used in this study. The reflection coefficient is measured at range operating frequency of $8 \mathrm{MHz}$ to $5 \mathrm{GHz}$. The relationship between dielectric constant and $S_{11}$ is determined. The other variables are compared during $\mathrm{S}_{11}$ at resonance. $\mathrm{S}_{11}$ of oranges is the highest at $2.6 \mathrm{GHz}$ with a value of $-42.84 \mathrm{~dB}$.
\end{abstract}

Keywords:citrus; monopole antenna; reflection coefficient.

Author Correspondence, e-mail: rafidah504@salam.uitm.edu.my doi: http://dx.doi.org/10.4314/jfas.v9i4s.36

\section{INTRODUCTION}

Citrus fruit production in the world has been recorded 121 million ton in 2014. As shown in table below, the production all types of citrus are increasing over the years. This is either due to increase in population or improvement in method of farming [1]. 
Table 1.World production of different type of citrus

\begin{tabular}{cccccc}
\hline Year & \multicolumn{5}{c}{ Production of Different Type of Oranges in Thousand Tonnes } \\
& Citrus & Orange & Tangerine & Lemon and Lime & Grape-Fruit \\
\hline $1981 / 82$ & 58891.7 & 39757.5 & 9181.9 & 5843.0 & 4166.8 \\
$1989 / 90$ & & & & & \\
$1991 / 92$ & 84209.1 & 56005.7 & 14046.8 & 8521.9 & 5296.9 \\
$1999 / 00$ & & & & & \\
$2007 / 08$ & 110048.6 & 67918.5 & 23014.9 & 12520.3 & 6594.8 \\
$2008 / 09$ & 113310.2 & 69236.0 & 24908.4 & 12924.8 & 6518.9 \\
$2009 / 10$ & 114724.0 & 70346.3 & 26724.8 & 12756.8 & 6582.5 \\
$2010 / 11$ & 121206.3 & 70592.8 & 26512.3 & 13414.3 & 6780.5 \\
$2011 / 12$ & 121400.4 & 69865.4 & 28579.6 & 13303.5 & 7033.8 \\
$2012 / 13$ & 119164.4 & 671947.7 & 29400.9 & 12943.4 & 7233.9 \\
$2013 / 14$ & 121273.2 & 68925.2 & 31203.9 & 13172.3 & 7625.4 \\
\hline
\end{tabular}

Orange has been imported in Malaysia more than any other type of citrus, while some species of citrus originated from Malaysia. Citrus species are grown in industry orchards, backyard orchards and some collection in Malaysia [2-3].

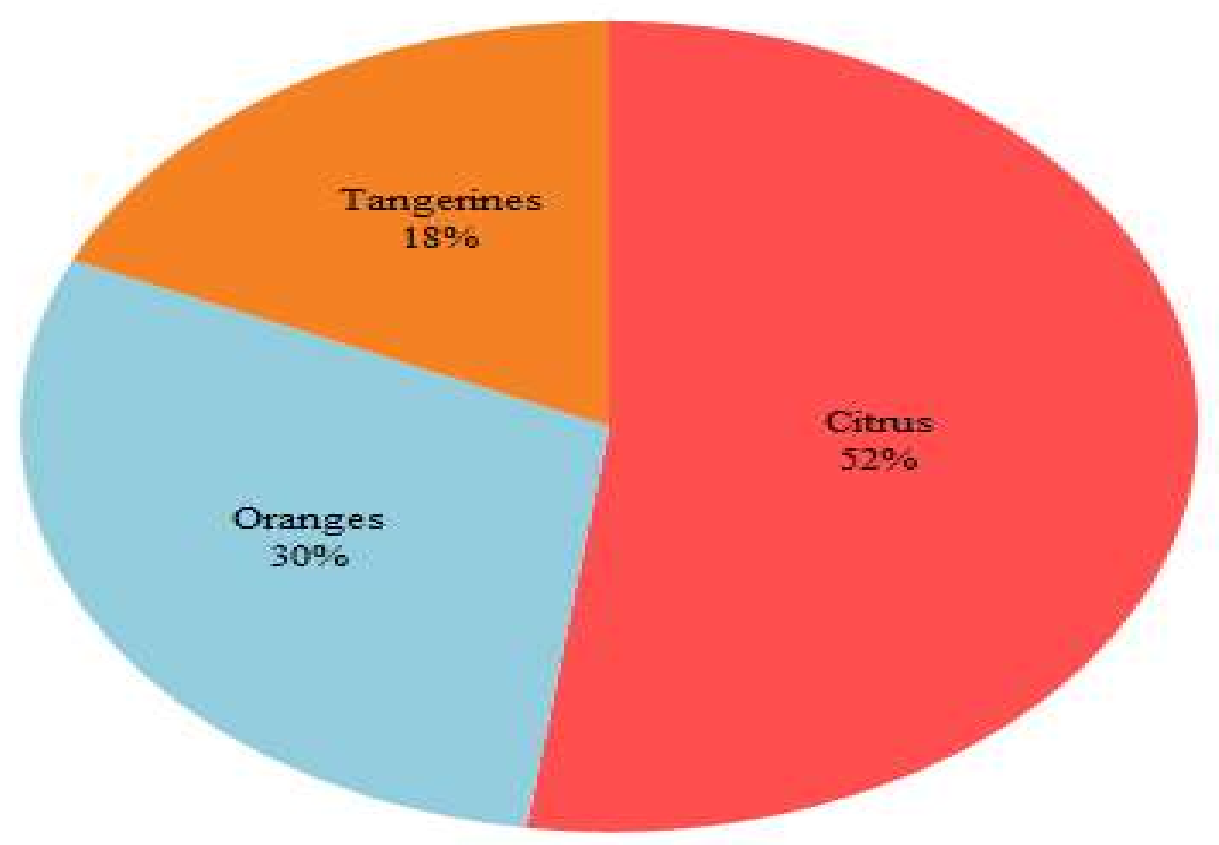

Fig.1. Percentage of different type of citrus being imported in 2014 


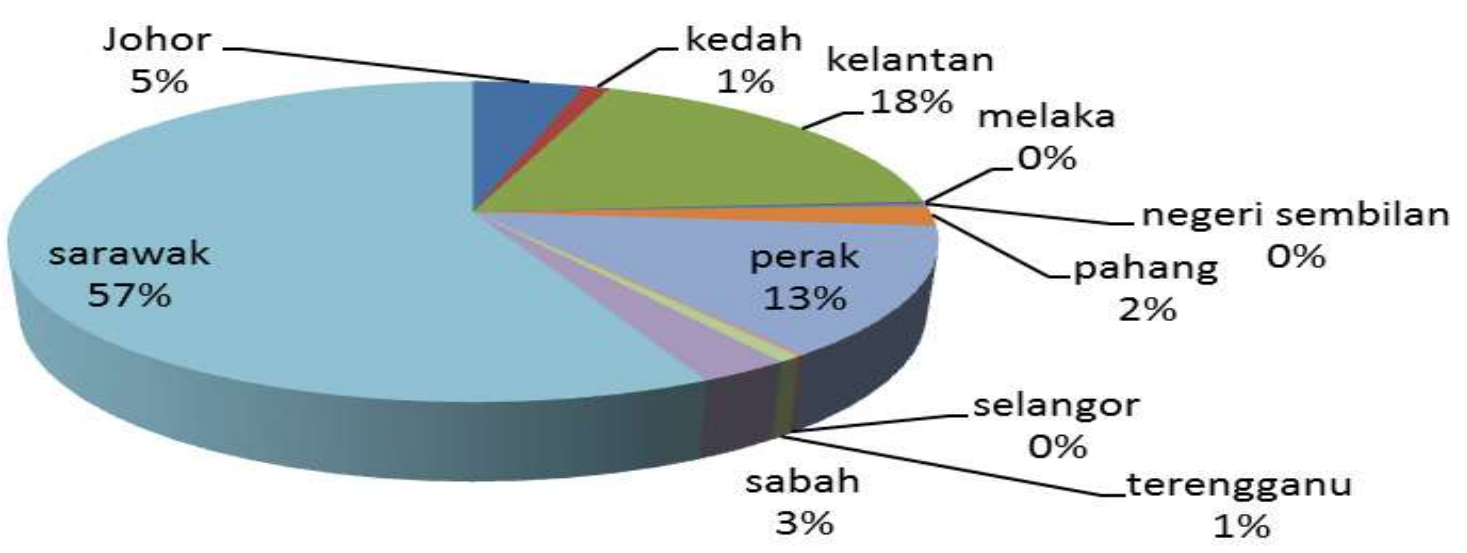

Fig.2. Percentage of production for citrus at different states in Malaysia

Fig. 1 shows the percentage of different type of citrus being imported in 2014. Compared to oranges and tangerines, Malaysia imported citrus 52\%. This number keeps on increasing over the years. Fig. 2 shows percentage of production for citrus at different states in Malaysia. Sarawak contributes the most production of citrus which is $57 \%$.

Microwave application has been widely used in many different areas. Hence, the existing state of microwave technology becomes an interest subject in agriculture-related industries [4]. From industrial perspective, this technique may be beneficial as it is safe, non-destructive and in most instances contactless [5].

The dielectric properties of a material are intrinsic properties usually expressed by the relative complex permittivity, $\varepsilon_{\mathrm{r}}=\varepsilon_{\mathrm{r}}{ }^{\prime}-\mathrm{j} \varepsilon_{\mathrm{r}}$ " where $\varepsilon_{\mathrm{r}}{ }^{\prime}$ is the dielectric constant and represents the ability of a material to store electric energy, and $\varepsilon_{\mathrm{r}}$ " is the loss factor and represents the loss of electric-field energy in the material [6].

The dielectric constant and loss factor as well as the loss tangent of moist substances are generally dependent on frequency, temperature, density, moisture content and other factors such as the material structure and composition and the binding modes of water molecules which are known to be important but for which no data are available for quantification [7].

In [8] built up a technique to decide the dielectric property by measuring the sizes of the reflection and coupling coefficients of the coupled radio wires. The test was led at $2.45 \mathrm{GHz}$ to approve the reenactment of coupled dipoles over a dielectric half space. Thus, the proposed system is discovered compelling. The decisively refection size and coupling coefficient of the coupled radio wires influences the microwave estimations of the dielectric properties of medium test.

In [9] utilized same procedure for various reason for a similar kind of organic product (tangerine and granulated orange). For the tangerine particularly, the principle goal is to 
characterize the tangerine as per flavor and with respect to granulated orange, faulty order is the point of their exploration. By utilizing the system of microstrip fix receiving wires, the recreation is done to recognize the relating reenacted coupled signs of $|\mathrm{S} 11|,|\mathrm{S} 41|,|\mathrm{S} 51|$ and |S61| after the power locators were $0.3441,0.0894,0.0521$ and 0.0908 individually.

On the other hand, the mean values of $\left|S_{11}\right|,\left|S_{21}\right|,\left|S_{31}\right|$ and $\left|S_{41}\right|$ are 0.068, 0.192, 0.137 and 0.054. The mean values of granulated oranges for S1 1 and S31 increases, while those for S21 and S41 decreases. These varieties can be utilized as pointers for distinguishing granulation. By and large the result is exceptionally potential. This is on the grounds that testing of the sensor [11] exhibited a mistake rate of just $4.53 \%$ and the utilization recommending it has potential for use in characterizing tangerine organic products by sweetness. Additionally, the utilization of measured mean and standard deviation of S-parameters can order the deserted orange like a granulated orange. Hence, this paper is focused on the brix level of local oranges at resonance frequency.

\section{MATERIAL AND METHOD}

40 oranges (limaumadu) are bought from a local fruit seller. These samples are being kept at temperature of $26 \mathrm{C}$. They are weighed by an electronic balance. The fruits were numbered according to their weight on the first day. The weight and diameter is measured and recorded every day.

\subsection{Non-Destructive Method}

The proposed method in this study is microwave technique. This method is used to determine the reflection coefficient S11 of local oranges fruit. It is done by connecting the cabanR54 reflectometer to a personal computer. The sample is then touched to the antenna attached at the end of reflectometer.

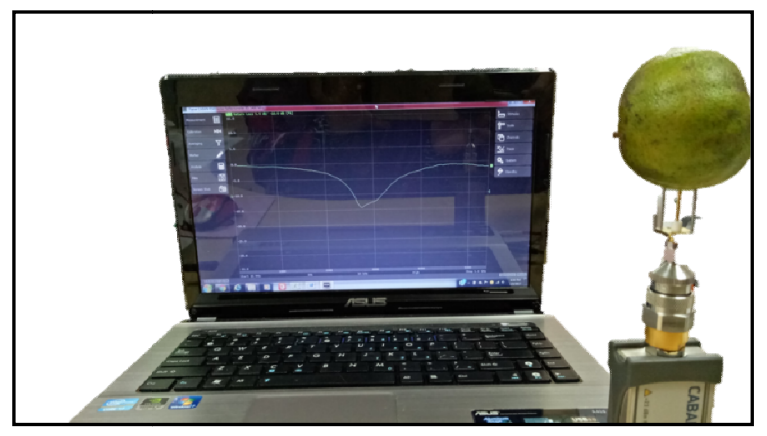

Fig.3. $\mathrm{S}_{11}$ is being measured using CABANR54 


\subsection{Destructive Method}

It is a crucial part in this study. During this method, the brix, acidity, $\mathrm{pH}$ and moisture content is identified. Brix and acidity can be obtained by using digital hand-held pocket refractometer (Hybrid PAL-BX|ACID F5 ATAGO).
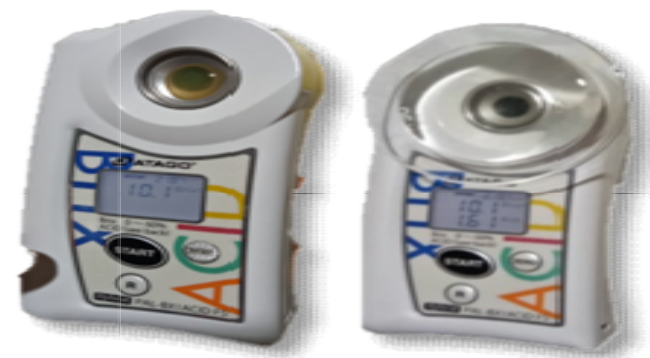

Fig.4. (Left) Refractometer shows the reading of Brix (Right) Refractometer shows the reading of Brix and acidity

The $\mathrm{pH}$ of orange juice is measured with a Combo $\mathrm{pH} / \mathrm{EC} / \mathrm{TDS} / \mathrm{Temperature}$ with Only One Tester (Model HI 98129). Then, oranges pulps' and juices' were placed back into their skins. These oranges were left in an oven. After 24 hours, the weights of dried oranges were measured. This measurement is done to compute the moisture content of oranges.

\section{RESULTS AND DISCUSSION}

\section{1. $S_{11}$ on Air and $S_{11}$ of Oranges}

The $\mathrm{S}_{11}$ is measured when antenna is propagates on air [10].

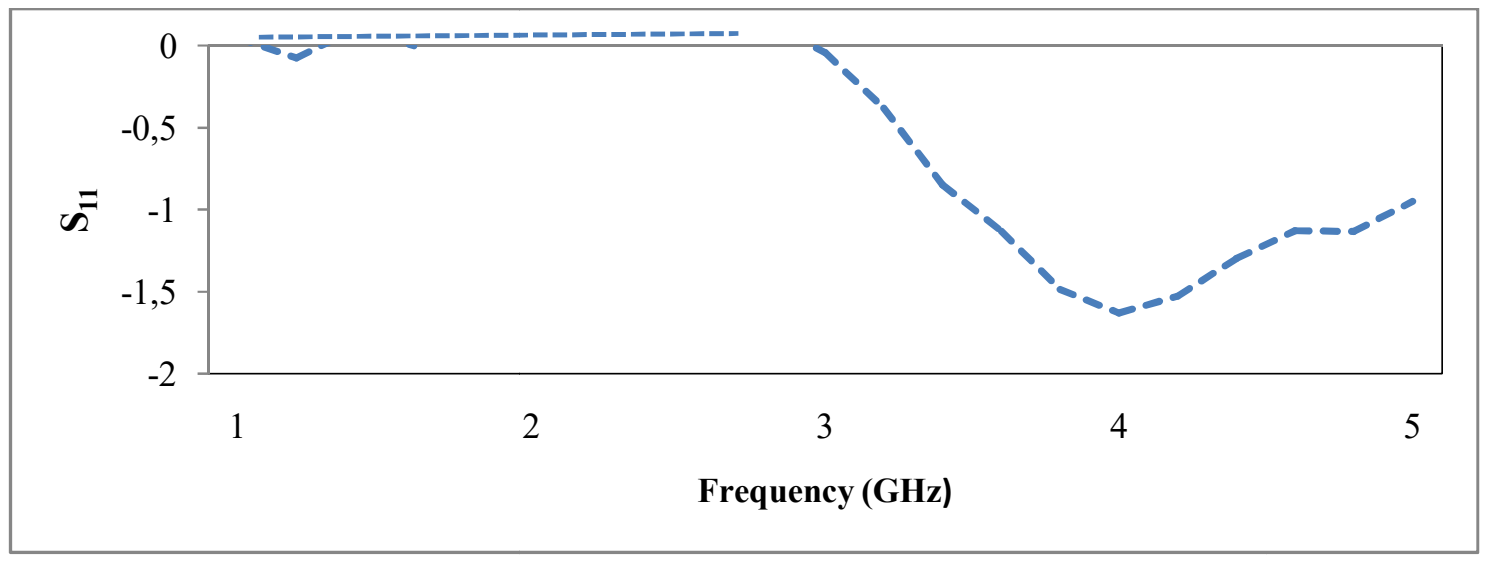

Fig.5.CABANR54 measurement of $\mathrm{S}_{11}$ on air

Its peak value is at the frequency of $4 \mathrm{GHz}$ and having a magnitude of $-1.63 \mathrm{~dB}$. Then, the magnitude of reflection coefficient of each orange is observed from day 1 to day 7 . From the measurements of magnitude by using network analyzer, the highest peak value is $-42.84 \mathrm{~dB}$ during day 1 at $2.6 \mathrm{GHz}$. 


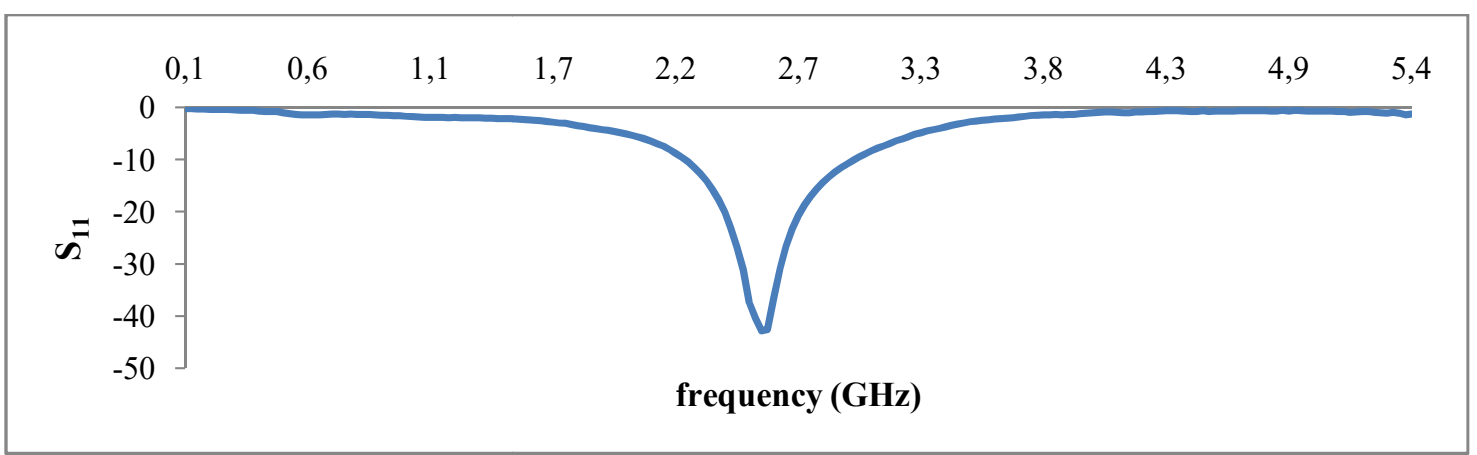

Fig.6.CABANR54 measurement of $\mathrm{S}_{11}$

At different days, the peak magnitude of each orange I observed. These values are considered as $\mathrm{S} 11$ at resonance. Averagely these peaks are located around $2.2 \mathrm{GHz}$ to $2.6 \mathrm{GHz}$. Hence, these resonance frequencies are chosen to observe their relationship with $\varepsilon_{\mathrm{r}}$, brix, acidity, $\mathrm{pH}$ and moisture content, MC.

\subsection{Relationship between $\varepsilon_{\mathrm{r}}$ and $S_{11}$ at Resonance}

Based on the magnitude of reflectance coefficient, $\Gamma$, relative permittivity $\varepsilon_{\mathrm{r}}$, is calculated by using the formula $[7,11]$ :

$\Gamma=\frac{1-\sqrt{\varepsilon_{r}}}{1+\sqrt{\varepsilon_{r}}}(1)$

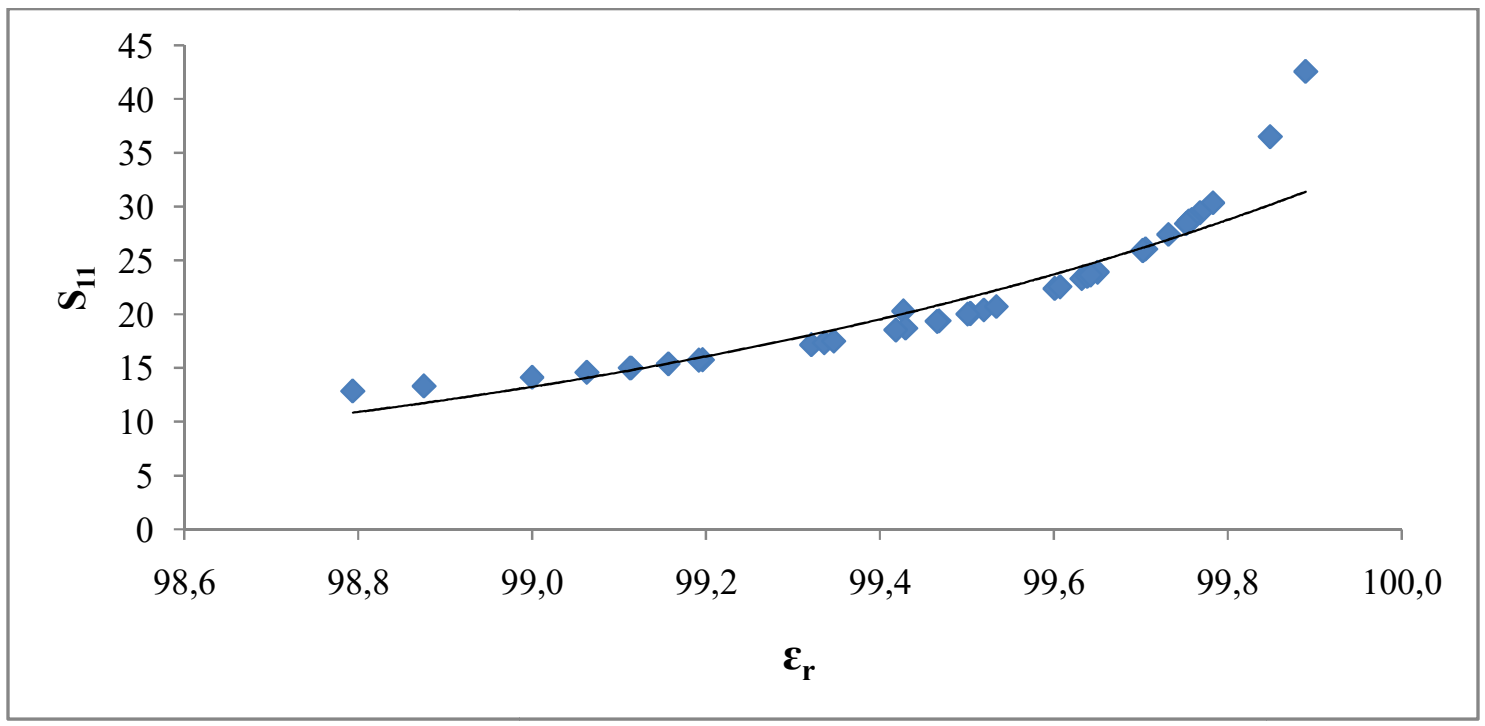

Fig.7. $\varepsilon_{\mathrm{r}}$ and $\mathrm{S}_{11}$ at resonance

Fig. 7 illustrates the relationship between relative permittivity and reflection coefficient at resonance. The permittivity values of oranges are ranging from 98.8 to 99.9 . The average permittivity value is 99.5 . This shows that at resonance frequency, the permittivity value is high. It also can be observed that at higher $\mathrm{S}_{11}, \varepsilon_{\mathrm{r}}$ also increases exponentially. 


\subsection{Comparison with Parameters during Destructive Measurements}

Destructive measurement is done to support the results obtained during the non-destructive process. Destructive method means that the oranges are squeezed to get the juice. Then, brix, acidity and $\mathrm{pH}$ can be measured from the juice.

Fig. 7-9 show the relationship between $\mathrm{S}_{11}$ at resonance and with brix, acidity and $\mathrm{pH}$ respectively.

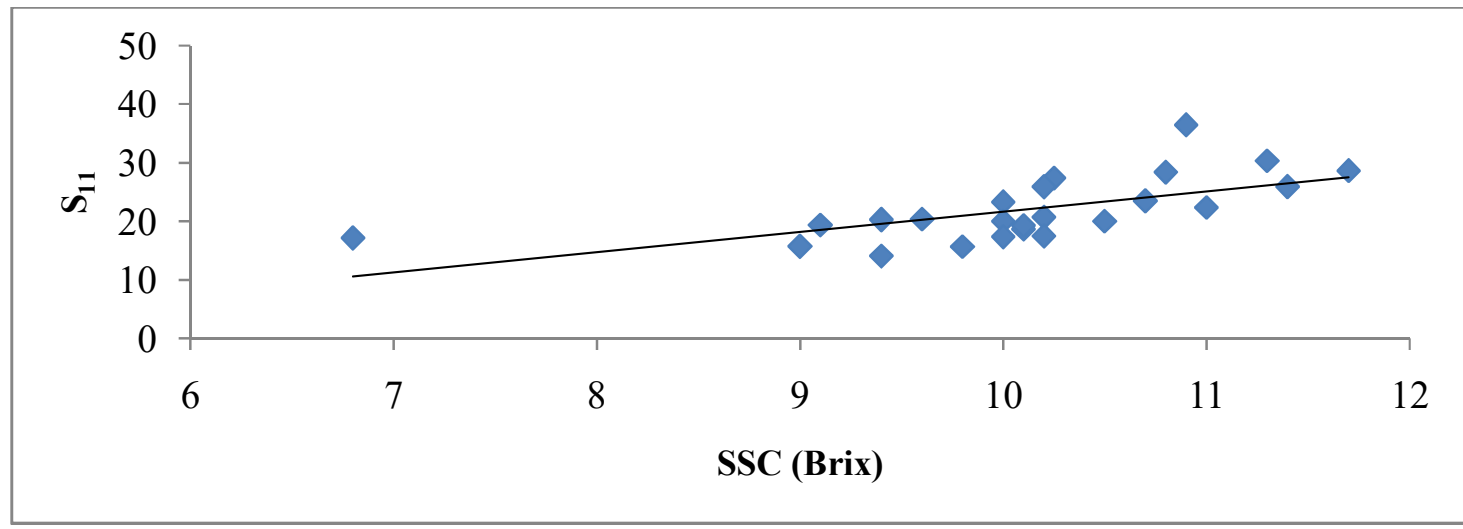

Fig.8. $\mathrm{SSC}$ and $\mathrm{S}_{11}$ at resonance

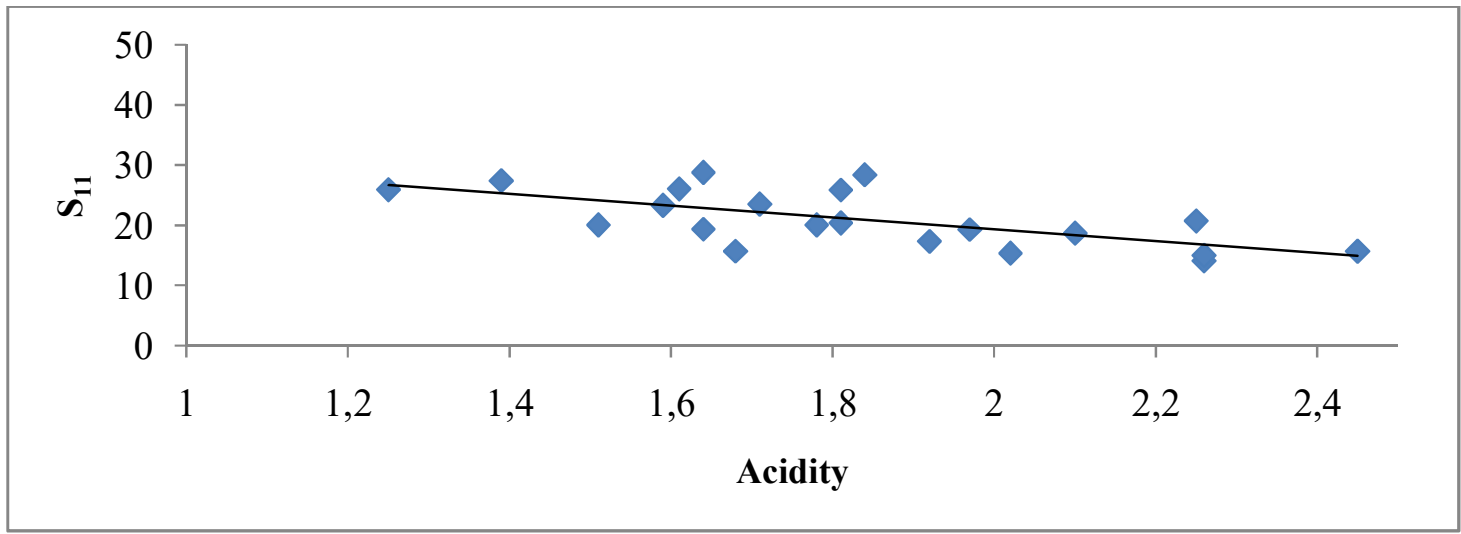

Fig.9. Acidity and $\mathrm{S}_{11}$ at resonance

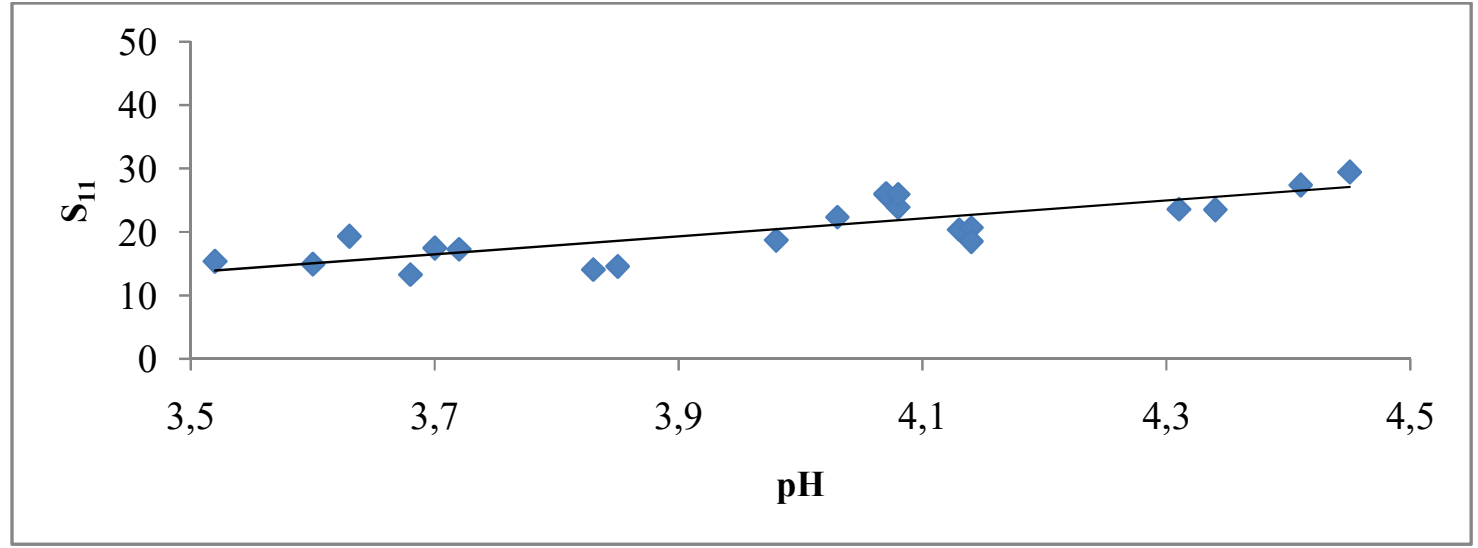

Fig.10. $\mathrm{pH}$ and $\mathrm{S}_{11}$ at resonance 
The final step in destruction method is the drying process of oranges. The percentage of MC can be obtained according to this relationship [5]:

$$
\mathrm{mc} \%=\frac{\mathrm{M}_{\text {initial }}-\mathrm{M}_{\text {dried }}}{\mathrm{M}_{\text {initial }}} \times 100 \%
$$

2)

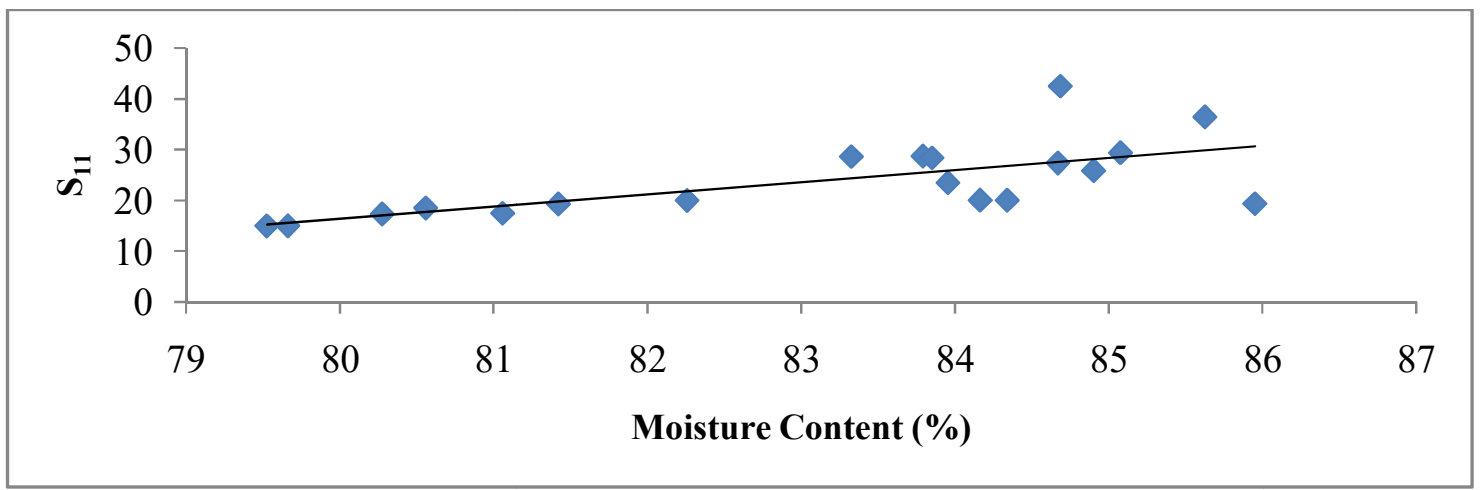

Fig.11. Moisture content and $\mathrm{S}_{11}$ at resonance

The equations representing the relationship between reflection coefficient and other variables at resonance are presented in Table 2.

Table 2.Multiple linear regression equations at resonance

\begin{tabular}{cc}
\hline Function & $\mathbf{R}^{\mathbf{2}}$ \\
\hline$\varepsilon_{\mathrm{r}}=2 \mathrm{E}-41 \mathrm{e}^{0.9712 \mathrm{x}}$ & 0.9122 \\
$\mathrm{SSC}=3.4622 \mathrm{x}-12.951$ & 0.4019 \\
Acidity $=-9.8498 \mathrm{x}+39.054$ & 0.4237 \\
$\mathrm{pH}=14.144 \mathrm{x}-35.804$ & 0.6525 \\
Moisture Content $=2.3887 \mathrm{x}-174.68$ & 0.4538
\end{tabular}

The equation and the determination $\mathrm{R}^{2}$ were obtained by applying regression analysis [12]. The function of $\varepsilon_{\mathrm{r}}$ has the highest value of $\mathrm{R}^{2}$. This gives better prediction of relationship $\mathrm{S}_{11}$ and $\varepsilon_{\mathrm{r}}$

\section{CONCLUSION}

The reflection coefficient is relatively related to all the measurements obtained. The relationships of each measurement are depicted as in the figures in the result section. Despite having a very good permittivity, other variables are only at average. But it is good enough to prove that this method can be used in determining the SSC of local oranges. This study can be improved in terms of result analysis and considering other factors that will contribute to the distinction of $\mathrm{S}_{11}$ of local oranges. 


\section{ACKNOWLEDGEMENTS}

This research was supported by Ministry of Higher Education in funding for Fundamental Research Grant Scheme (FRGS) under sponsorship file no. FRGS/1/2015/TK04/UITM/03/9 and Research Management Centre (RMC), UniversitiTeknologi MARA (UiTM) Shah Alam.

\section{REFERENCES}

[1] Ricker-Gilbert J, Jumbe C, Chamberlin J. How does population density influence agricultural intensification and productivity? Evidence from Malawi. Food Policy, 2014, 48:114-128

[2] Abdullah T, Shokrollah H, Sijam K, Abdullah S. Control of Huanglongbing (HLB) disease with reference to its occurrence in Malaysia. African Journal of Biotechnology, 2009, 8(17):4007-4015

[3] Food and Agriculture Organization of the United Nations (FAO). Citrus fruit statistics 2015. Rome: FAO, 2016

[4] Kraszewski AW. Microwaveaquametry-Needs and perspectives. IEEE Transactions on Microwave theory and Techniques, 1991, 39(5):828-835

[5] Trabelsi S, Kraszewski AW, Nelson SO. A microwave method for on-line determination of bulk density and moisture content of particulate materials. IEEE Transactions on Instrumentation and Measurement, 1998, 47(1):127-132

[6] Nelson SO, Bartley PG, Lawrence KC. Measuring RF and microwave permittivities of adult rice weevils. IEEE Transactions on Instrumentation and Measurement, 1997, 46(4):941-946

[7] Trabelsi S, Krazsewski AW, Nelson SO. New density-independent calibration function for microwave sensing of moisture content in particulate materials. IEEE Transactions on Instrumentation and Measurement, 1998, 47(3):613-622

[8] Mearnchu J, Limpiti T, Torrungrueng D, Akkaraekthalin P, Krairiksh M. Dielectric-property determination from measurement of magnitude of reflection and coupling coefficients of coupled antennas. In5th IEEE International Conference onElectrical Engineering/Electronics, Computer, Telecommunications and Information Technology, 2008, pp. 221-224 
[9] Leekul P, Chivapreecha S, Krairiksh M. Microwave sensor for defected fruit classification. InIEEE Conference on Antenna Measurements and Applications, 2015, pp. 1-2 [10]Ali AH, Abbas Z, Hassan J, Jusoh A, Zahari RB. Microwave antenna sensing technique for determination of moisture content in hevea latex from'HeveaBrasiliensis' tree. Australian Journal of Crop Science, 2011, 5(11):1326-1333

[11]Rosman R, Dimon MN, Yeow YK. CST simulation on monopole sensor for determination of malaysian local oranges sweetness quality non-destructively. InUKSim-AMSS 16th IEEE International Conference onComputer Modelling and Simulation, 2014, pp. 548-552

[12]Yee LK, Abbas Z, Jusoh MA, Yeow YK, Meng CE. Determination of moisture content in oil palm fruits using a five-port reflectometer. Sensors, 2011, 11(4):4073-4085

\section{How to cite this article:}

Ghazali H, Rosman R, Sharif Z. Measurement of brix level of malaysian local oranges at resonance frequency. J. Fundam. Appl. Sci., 2017, 9(4S), 629-638. 